\title{
OS SENTIDOS DA DIMENSÃO TÉCNICA: ABORDAGEM SOBRE A COMPETÊNCIA EM INFORMAÇÃO NO ÂMBITO DA FILOSOFIA E DA CIÊNCIA DA INFORMA̧ÇÃO
}

\author{
Alexandre Pedro de Oliveira \\ Mestre em Ciência da Informação pela Universidade Federal de Santa Catarina - UFSC \\ Email: alexandre.oliveira@ufsc.br
}

\begin{abstract}
Elizete Vieira Vitorino
Professora do Departamento de Ciência da Informação da Universidade Federal de Santa Catarina - UFSC Email: elizete.vitorino@ufsc.br
\end{abstract}

\begin{abstract}
Resumo
Investiga a temática competência em informação sob a ótica da Filosofia e da Ciência da Informação. Tem como diretriz a seguinte indagação: como é possível abordar a competência em informação no âmbito da dimensão técnica por meio de um diálogo integrado entre a Filosofia e a Ciência da Informação? As respostas a esta pergunta norteadora, bem como as reflexões resultantes destas, baseiam-se numa investigação de natureza exploratória e bibliográfica, conduzida em artigos e livros nestas áreas do conhecimento. Trata sobre a dimensão técnica, teoricamente constituída por conceitos sobre a "técnica" (Filosofia) e sobre a competência em informação (Ciência da Informação). Resgata conceitos de Aristóteles de Hannah Arendt e de outros filósofos contemporâneos, relacionando-os aos conceitos de competência em informação. A inter-relação conceitual revela que a dimensão técnica da competência em informação abrange habilidades sustentadas por julgamentos e decisões durante as etapas de busca, avaliação e uso da informação.
\end{abstract}

Palavras-chave: Competência em informação. Dimensão técnica da competência em informação. Virtudes. Ciência da Informação - Filosofia.

\section{THE MEANINGS OF THE TECHNICAL DIMENSION: INFORMATION LITERACY IN THE FIELDS OF PHILOSOPHY AND INFORMATION SCIENCE}

\begin{abstract}
The aim of this article is to investigate the issue of Information Literacy under the light of Philosophy and Information Science. The article's basis lies in the following inquiry: how is it possible to approach Information Literacy in the technical dimension through a dialogue between Philosophy and Information Science? The answers to this guiding question, as well as the deliberations that arise as an outcome, are based on a research that is both exploratory and bibliographical, carried out through the reading of articles and books in the field of study. This study addresses the technical dimension, supported by theoretical concepts dealing with Technique (Philosophy) and Information Literacy (Information Science). This research goes back to notions proposed by Aristotle, Hannah Arendt and other contemporary philosophers, relating these concepts to Information Literacy. The conceptual interrelation reveals that the technical dimension of Information Literacy tackles skills grounded on judgments and decisions made during the steps of location, evaluation and use of information.
\end{abstract}

Keywords: Information Literacy. Technical dimension of Information Literacy. Virtues. Information SciencePhilosophy.
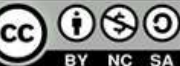

Esta obra está licenciada sob uma Licença Creative Commons Atribuição 4.0 Internacional (CC BY-NC-AS 4.0).

LOGEION: Filosofia da informação, Rio de Janeiro, v. 2 n. 2, p. 40-65, mar./ago. 2016. 


\section{Introdução}

El ser natural es el estado inercial del ser; el ser técnico es su estado dinámico. El estado inercial está aberto a futuro; el dinâmico, a porvenir

(GARCÍA BACCA, 1987, p.139).

A American Library Association (ALA), por intermédio do seu Centro para el Futuro de las Bibliotecas, identificou tendências relacionadas às bibliotecas e às comunidades atendidas por estas a fim de promover "técnicas de futuro" e de inovação para auxiliar profissionais da informação a construir conexões com questões emergentes. São 19 tendências (AMERICAN, 2015) organizadas em sete categorias: Sociedade, Tecnologia, Educação, Meio Ambiente, Política (e Governo), Economia e Demografia. Nota-se que há um "envelhecimento da sociedade", ou seja, uma mudança no perfil dos usuários de bibliotecas e o aumento da demanda por serviços e atividades para este grupo. Percebe-se uma tendência denominada "impacto coletivo" - os bibliotecários passam a ser considerados os principais parceiros em projetos sociais, e em programas de desenvolvimento da competência em informação, associando-se com organizações ou governos para tais questões. O uso de “drones”, também é mencionado, já que poderia favorecer o acesso à internet em áreas carentes e os esforços de divulgação de serviços. A tendência fast casual, assinala que os profissionais da informação podem criar espaços mais ativos e sociais nas bibliotecas e gerar experiências agradáveis aos usuários e fazê-los desenvolver um sentimento de pertencimento à unidade de informação que procura.

Como se pode constatar, a técnica está associada, neste estado dinâmico, a um “porvir” (tal qual assinala GARCÍA BACCA, 1987), mas também a um futuro que se apresenta agora. Não nos cabe aqui afirmar se as tendências ali apresentadas cabem aos diversos contextos e às variadas unidades de informação, até porque usuários também são “seres cambiantes". Mas há que se refletir sobre a técnica: conservar a mesma técnica ou fazer uma vez mais a mesma técnica? Faz-se necessário refletir sobre esse movimento de ir e vir da técnica .

Nosso objetivo, deste modo, é investigar o sentido da dimensão técnica da competência em informação sob a ótica da Filosofia e da Ciência da Informação. Esta dimensão é caracterizada em associação ao conceito sobre a competência em informação (VITORINO; PIANTOLA, 2011). Por outras palavras, o principal propósito deste trabalho é 
resgatar teoricamente alguns conceitos sobre técnica na Filosofia a fim de relacioná-los ao conceito da competência em informação e, assim, caracterizar aquela que consideramos constituir-se no suporte da competência, uma vez que se revela na ação dos profissionais - diz respeito a um domínio de saberes e de habilidades de diversas naturezas e que permite a intervenção prática na realidade (RIOS, 2006).

De forma abrangente e de certa maneira, até mesmo simplista, a competência em informação abrange a capacidade do indivíduo para acessar, avaliar e usar a informação a fim da solução de necessidades, problemas e "oportunidades" informacionais relacionados à execução das atividades cotidianas nos diferentes setores da nossa vida: educação, lazer, trabalho, saúde, entre outros. Mas é quando a competência em informação se relaciona com a técnica que se percebe a proporção que o tema pode alcançar. Para Liz (1995), a grande missão tradicionalmente encomendada à técnica, tem sido a de resolver os problemas práticos dos indivíduos e de satisfazer seus interesses atuando na realidade. Para o autor, os conceitos de técnica (e de tecnologia, inclusive, muitas vezes usada erroneamente como sinônimo de técnica) e seus derivados são enormemente ambíguos. A técnica é, em primeiro lugar, sistemas de ações articuladas segundo regras de caráter social, ou seja, não se relacionam a ações isoladas e ocasionais.

O vocábulo técnica, por sua vez, inclui diferentes conceitos: indica algo que pode ser fabricado pelo homem (poíesis) (GIACOIA JUNIOR, 2006), um conjunto de regras para executar alguma atividade (ABBAGNANO, 2007), ou até mesmo a habilidade do indivíduo para atingir um fim (PERRIN,1996). Também corresponde à dimensão prática do ser humano, composta pela poíesis e a práxis (intenção daquele para agir) (NEDEL, 2007).

Nossa investigação, deste modo, procura apresentar a técnica sob um olhar ainda não desenvolvido na literatura em Ciência da Informação: esclarecê-la sob um aspecto reflexivo e não puramente prático. Isso vai ao encontro de detalhar o vocábulo "técnica", cujas autoras Vitorino e Piantola $(2009$; 2011) revelaram tratar-se da dimensão técnica da competência em informação e que se constitui numa das quatro dimensões pelas quais a temática pode ser estudada. Técnica, estética, ética e política: cada dimensão apresenta suas características e relevância próprias, e, em equilíbrio, consistem nas bases para o desenvolvimento desta "metacompetência" no indivíduo. Mas, é na dimensão técnica, que tem como base a habilidade para buscar, avaliar e usar a informação, que encontramos a "dimensão suporte". Outros aspectos/significados também estão presentes no vocábulo "técnica", e 
consequentemente respaldam um olhar atento sobre este termo ainda carente na literatura em Ciência da Informação.

Por meio desta constatação, nos tornamos motivados a adentrar e explorar o território da competência em informação com o olhar voltado à Filosofia, e assim contribuir para o fortalecimento dessa temática em nível nacional.

Ademais, esta pesquisa classifica-se como exploratória por demonstrar uma visão geral e aproximada sobre determinado fato (GIL, 2008). Também bibliográfica, por englobar itens, tais como artigos, livros, capítulos de livros, dentre outras fontes informacionais a fim de induzir o pesquisador ao contato direto com determinado assunto (MARCONI; LAKATOS, 2012). E, para isto, partimos da seguinte indagação: como é possível abordar a competência em informação no âmbito da dimensão técnica por meio de um diálogo integrado entre Filosofia e Ciência da Informação?

Para desenvolver a pesquisa bibliográfica sobre a dimensão técnica da competência em informação, inicialmente buscamos nos dicionários de Filosofia "conceitos gerais" sobre a técnica que apontaram para os termos "poíesis e práxis", isto é, significam, respectivamente, a ação do homem para produzir um fim (objeto), e a ação do homem para atingir um fim (agir ético) diante da sua atividade política na sociedade.

Consequentemente, "elegemos", ou melhor, determinamos os filósofos que tratam desse tema, e que poderiam "conversar/dialogar" com os autores da área da Ciência da Informação: a técnica sob o pensamento de Aristóteles (2003) e Hannah Arendt (2010).

Neste sentido, o artigo utiliza da revisão de literatura na área da Filosofia e da competência em informação a fim de caracterizar os sentidos da técnica na Filosofia, a dimensão técnica da competência em informação, e, algumas considerações sobre diferentes conceitos identificados na literatura.

\section{0 sentido da técnica na filosofia}

La técnica em cuanto actual, es técnica de innovaciones. La técnica, em cuanto clásica, es técnica de renovaciones (GARCÍA BACCA, 1987,

p.150).

Para compreender o vocábulo "técnica", há que se recorrer a filósofos de outras épocas, tais como Aristóteles (2003), para quem a técnica se constitui numa das virtudes 
intelectuais. Autores brasileiros e de época atual também discorrem sobre o tema, tais como Schio (2012), a qual aborda o pensamento de Hannah Arendt, que mesmo voltado à política, se revela enriquecedor quanto à poíesis e a práxis. Estes trabalhos se dedicam apresentar o vocábulo técnica sob o foco da Filosofia antiga (período que abrange o século VI a.C. ao século VI d.C.) e contemporânea (século XIX aos dias atuais). Assim, este recorte teórico estabelecido na Filosofia possibilita realizar uma relação com a Ciência da Informação, cuja finalidade é demonstrar o vínculo entre competência em informação e técnica, e assim fornecer subsídios para caracterizar e compor a dimensão técnica da competência em informação.

\subsection{A técnica em Aristóteles e Hannah Arendt}

Quando tratamos de técnica, uma obra nos parece refletir aquilo que se apresenta como sentido para o termo: Aristóteles (384-322 a.C ) ${ }^{1}$ e sua "Ética a Nicômaco". Na obra, o filósofo reflete sobre a ação humana: como o indivíduo pode agir do melhor modo possível em consonância com o equilíbrio das suas virtudes. Para Aristóteles toda ação visa a um fim ou a uma finalidade:

[...] entre os fins se observa uma certa diversidade: alguns são atividades, outros são produtos distintos das atividades das quais resultam [...] Mas como muitas são as ações, artes e ciências muitas são suas finalidades. O fim da medicina é a saúde, o da construção naval é um navio, o da estratégia militar é a vitória (ARISTÓTELES, 2003, p. 17).

Este trecho expõe o campo da atividade humana formado pela práxis e poíesis. Mostram-se dois tipos de fins na ação: o fim em si próprio, como por exemplo, o agir ético (o resultado da ação está na própria atividade) e o fim que visa uma obra resultante da ação, como por exemplo, a casa como o produto da atividade da construção. Estes aspectos, práxis e poíesis, especificamente se associam na abordagem das virtudes intelectuais, como partes integrantes da alma humana.

A fim de compreender a natureza das virtudes, o filósofo descreve a composição da alma $\left(P s y k h e^{2}\right)$ humana, quanto aos aspectos da virtude moral e intelectual. Para Aristóteles

\footnotetext{
${ }^{1}$ Para uma melhor compreensão, complementaremos as ideias deste filósofo com as publicações de autores contemporâneos.

${ }^{2}$ Lugar que reside pensamentos, sentimentos e desejos (CHAUI, 2002).
} 
(2003), a alma humana contém a parte racional (virtudes intelectuais) ${ }^{3}$ e a parte desprovida de razão. A parte irracional da alma constitui aquela que correspondente à nutrição e ao crescimento (natureza vegetativa) - todos os seres vivos a possuem. Outro elemento irracional é o desiderativo (desejos) também comum a outros seres vivos. Entretanto, para Aristóteles (2003) concomitantemente este elemento também participa do princípio racional da alma, pois os seres humanos possuem a condição de controlar-se perante um desejo.

É aí então, que o filósofo demonstra o que é específico do homem em relação aos outros seres vivos: a razão. Ao expor as partes da alma, classificando-as em virtudes moral e intelectual o filósofo assegura que a virtude moral, fundamenta-se no domínio dos impulsos (desejos), também chamada de virtude ética, e que a virtude dianoética se refere à parte estritamente racional (NODARI, 2010). A virtude intelectual surge do ensino, o que requer experiência e tempo, enquanto a virtude moral resulta do hábito (ARISTÓTELES, 2003).

Consequentemente os elementos racionais e irracionais da alma são os responsáveis pela formação das virtudes e que influenciam as nossas ações. Sob este olhar, Aristóteles (2003, p. 49) conceitua a virtude como: “[...] uma disposição de caráter relacionada com a escolha de ações e paixões ${ }^{4}$, e consiste numa mediania, isto é, a mediania relativa a nós, que é determinada por um princípio racional próprio do homem dotado de sabedoria prática”.

Isto porque a virtude "[...] é ação, atividade da vontade que delibera e escolhe segundo a orientação da razão, a qual determina os fins racionais de uma escolha, com vista ao bem do agente, isto é, sua felicidade" (CHAUI, 2002, p. 447).

Entendemos que a virtude compreende o caráter que o ser humano revela diante de uma situação, ou seja, o modo de agir sob a orientação da razão, para decidir sobre seus atos e assim atingir um fim. Conforme Aristóteles (2003, p. 48): “[...] segue-se que a virtude deve ter a qualidade de visar ao meio-termo. Falo da virtude moral, pois é ela que se relaciona com as paixões e ações, e nestas existe o excesso, carência e um meio-termo". Nesta afirmação, encontramos o princípio da moderação: “é um meio-termo entre dois vícios ${ }^{5}$, um por excesso e o outro por falta, pois nos vícios ou há falta ou há excesso daquilo que é conveniente no que concerne às ações e às paixões, ao passo que a virtude encontra e escolhe o meio-termo" (ARISTÓTELES, 2003, p. 49).

\footnotetext{
${ }^{3}$ Parte racional da alma corresponde às virtudes intelectuais, explorada e descrita por Aristóteles (2003) no Livro VI de Ética a Nicômaco.

${ }^{4}$ Os sentimentos acompanhados do prazer ou sofrimento, como por exemplo, alegria, medo, desejo, ódio entre outros (ARISTÓTELES, 2003)

${ }^{5}$ Vício é o que corrompe a disposição de caráter (CAEIRO, 2009). É o que desequilibra as ações do ser humano, justamente pelo excesso ou deficiência.
} 
Um exemplo relativo ao princípio da moderação é a virtude da coragem, situada entre dois extremos (vícios), um por excesso e o outro por carência: "O homem que tem medo e de tudo foge, não enfrentando nada, torna-se um covarde; e de outro lado, o homem que não teme nada e enfrenta todos os perigos torna-se temerário" (ARISTÓTELES, 2003, p. 42). O homem covarde representa o vício da carência pela falta de coragem no enfrentamento das situações, e o temerário, aquele que excede nos atos corajosos. Portanto, ser corajoso indica a medida certa para a disposição dos nossos atos frente às situações que solicitam o exercício desta virtude: é a moderação, o meio-termo. Portanto, virtude consiste no encontro de uma boa medida em relação aos nossos atos, ou seja, a moderação e o equilíbrio destes.

Alcançar a moderação em nossos atos envolve a escolha deliberada (ZINGANO, 2008). Segundo este autor: "O padrão desta escolha é aquele feito pelo prudente, que pesa razões rivais e, vendo a verdade nas circunstâncias em que se produz a ação, decide-se por isto de preferência àquilo" (ZINGANO, 2008, p. 129). Neste sentido, a escolha por deliberação se relaciona com a virtude, do mesmo modo, com o desejo. "Além disso, o desejo se relaciona com os fins, e a escolha com os meios. Por exemplo, desejamos ter saúde, mas escolhemos os atos que nos tornarão saudáveis" (ARISTÓTELES, 2003, p. 61).

Assim sendo, a escolha dos nossos atos é uma decisão que ocorre na deliberação. Por sua vez, o desejo está em sintonia tanto com a escolha quanto com a deliberação. Portanto, de acordo com Aristóteles (2003, p. 64):

"[...] a escolha é um desejo deliberado de coisas que estão ao nosso alcance" e: sendo, então, os fins aquilo que desejamos, e os meios aquilo sobre o que deliberamos e que escolhemos, as ações relativas aos meios devem concordar com a escolha e ser voluntárias. Ora, o exercício da virtude relaciona-se com os meios; portanto, a virtude também está ao nosso alcance, da mesma forma que o vício. Com efeito, quando depende de nós o agir, igualmente depende o não agir, e vice-versa (ARISTÓTELES, 2003, p. $65)$.

Deliberamos e escolhemos movidos pelo desejo de alcançar determinado fim. Neste sentido, agir de forma boa ou má depende da nossa intenção. Consequentemente, somos responsáveis por nossas virtudes como também pelos vícios (ARISTÓTELES, 2003). Para superar e/ou dominar os sentimentos e vícios, torna-se necessário o indivíduo ceder espaço à razão, para que ocorra o correto exercício das virtudes, ou seja, o agir virtuoso (bom/justo). Nodari (2010, p. 28) acentua que "[...] a virtude ética é a justa medida que a razão impõe a sentimentos, ações ou atitudes que, sem o controle da razão, tenderiam para um ou outro 
excesso". Segundo o autor a virtude ética está subordinada às virtudes intelectuais, pois é pela presença da sabedoria prática que nos orientamos e determinamos o justo meio (moderação) das nossas ações. A virtude intelectual empresta à virtude moral o modo adequado para agir (moderação) e assim atingir os fins. Aristóteles (2003) expõe cinco virtudes vinculadas à parte racional: a arte, o conhecimento científico, a sabedoria prática, a sabedoria filosófica e a razão intuitiva (ARISTÓTELES, 2003).

Estas virtudes perfazem dois âmbitos (partes) da razão: a parte científica ${ }^{6}$ e parte calculativa $^{7}$ (ARISTÓTELES, 2003). A primeira, a teorética, é a parte com a função investigativa, e a segunda, deliberativa, a parte responsável pela reflexão e ponderação (WOLF, 2010). No âmbito da parte teorética: o conhecimento científico (que pode ser ensinado e demonstrado), a razão intuitiva (inteligência para apreender a ciência) e a sabedoria filosófica (junção do conhecimento científico com a razão intuitiva) são consideradas virtudes (ARISTÓTELES, 2003). Estas virtudes são responsáveis pela disposição racional do homem em conhecer e entender, e a última delas, a sabedoria filosófica, está voltada à atividade contemplativa, isto é, o conhecer pelo conhecer (CHAUI, 2002).

$\mathrm{Na}$ parte deliberativa, temos a sabedoria prática e a arte. A sabedoria prática (phrónesis) envolve a deliberação: "por conseguinte, em sentido geral, também a pessoa que é capaz de deliberar possui sabedoria prática” (ARISTÓTELES, 2003, p. 132). Além disso, esta virtude é uma disposição racional para agir no que é bom ou mau para o homem. Implica na emissão de ordens no que deve ou não ser feito na ação (ARISTÓTELES, 2003). O que caracteriza um indivíduo que possui sabedoria prática, isto é, um indivíduo prudente (CHAUI, 2002) é a reflexão que auxilia a deliberar corretamente e assim agir de modo virtuoso diante de uma situação. Nesta linha de pensamento, a sabedoria prática orienta o ser humano a agir bem, isto é, a ter uma ação virtuosa.

$\mathrm{Na}$ exposição acerca desta virtude, o filósofo estabelece também a diferença entre a sabedoria prática e a arte, ao apresentar os sentidos de práxis e poíesis: "com efeito, enquanto produzir tem uma finalidade diferente do próprio ato de produzir, o mesmo não ocorre com o agir, pois a finalidade da ação está na própria ação" (ARISTÓTELES, 2003, p. 132). A sabedoria prática visa à orientação na deliberação dos atos a serem realizados, isto é, uma razão orientadora para o agir diante do contingente (a finalidade da ação está em si mesma).

\footnotetext{
${ }^{6}$ Também conhecida como parte teorética ou pensante (WOLF, 2010).

${ }^{7}$ Parte prática ou deliberativa (WOLF, 2010).
} 
$\mathrm{Na}$ arte são prescritos métodos e/ou regras, ou seja, "ações moldadas" que servem como meio para atingir determinado fim de produção.

Por sua vez: "toda arte relaciona-se à criação e ocupa-se em inventar e em estudar as maneiras de produzir alguma coisa que pode existir ou não, e cuja origem está em quem produz, e não no que é produzido" (ARISTÓTELES, 2003, p. 131). Já a práxis é uma disposição racional para o agir, e este permanece com o sujeito para aperfeiçoá-lo conforme o tempo (experiência). Apesar da distinção destas virtudes intelectuais na parte deliberativa, tanto a práxis quanto a poíesis possuem em comum a capacidade do ser humano em raciocinar. Evidentemente há um parentesco entre ambas por pertencerem à dimensão prática do ser humano (NEDEL, 2007; WOLF, 2010).

Destarte, podemos visualizar a distinção entre as virtudes éticas e as virtudes intelectuais, por meio da Figura 1 que compõe o pensamento aristotélico.

Figura 1 - Composição das virtudes éticas e intelectuais.

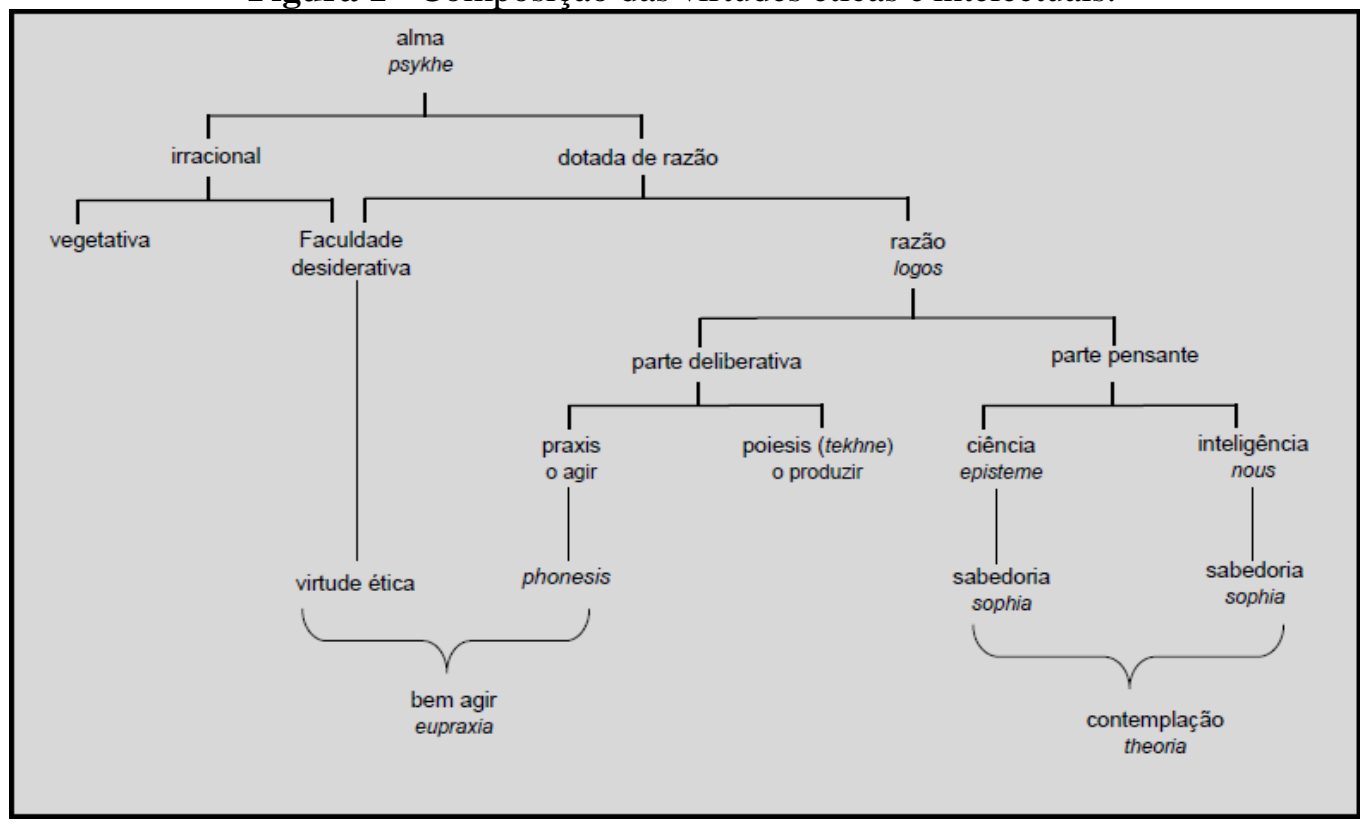

Fonte: Adaptado de Wolf (2010)

Com base nesta figura, para que o ser humano disponibilize boas ações e/ou atos virtuosos, ou melhor, aja bem (moralmente), torna-se necessária a virtude intelectual para orientação e encontro da "medida certa" (nem excesso, nem carência) dos atos humanos.

Não somente na obra de Aristóteles consta a técnica (saber fazer). Do mesmo modo, Hannah Arendt aborda esta questão ao nos apresentar as atividades que condicionam a 
existência do homem: o labor, o trabalho e a ação ${ }^{8}$, pertencentes à vita activa. Esta expressão corresponde à “[...] vida humana na medida em que está ativamente empenhada em fazer algo [...] sempre enraizada em um mundo de homens ou de coisas feitas pelos homens" (ARENDT, 2010, p. 26). A vida ativa indica, respectivamente, a atividade humana, o contexto da práxis, $a$ dimensão ética e a dimensão política que orientam e regem a ação do homem, e a poíesis, ação que permeia "o fazer" dos objetos para inseri-los ao mundo. Segundo Arendt (2010) a atividade do trabalho permite a construção do mundo, constituído por coisas duráveis. Neste, também se encontram os bens de consumo incessantes, destinados à sobrevivência dos seres humanos. Por sua vez, a atividade do trabalho finda no momento que o objeto está materializado (acabado), pronto para sua inserção no mundo, diferentemente da atividade do labor que "[...] move-se sempre no mesmo círculo prescrito pelo processo biológico do organismo vivo" (ARENDT, 2010, p. 121). O trabalho corresponde a um processo que finda em produtos duráveis e úteis para a construção do mundo, enquanto o labor diz respeito à atividade de subsistência, isto é, produzir para logo consumir assegurando o processo vital e à sobrevivência humana.

Além de estar vinculado ao metabolismo do homem como condição para a vida humana, também o labor se torna uma condição para a atividade do trabalho, pois é por meio dele que o homem se mantém vivo, e assim, constrói objetos na edificação do mundo. Neste sentido, para Arendt (2010, p. 167): “O mundo, o lar construído pelo homem na Terra e fabricado com o material que a natureza terrena coloca à disposição de mãos humanas, consiste não de coisas que são consumidas, mas de coisas que são usadas”.

Para fabricar coisas/objetos, há o processo de reificação que consiste na retirada da matéria-prima natural para transformá-la em material, “[...] como no caso da árvore, que tem de ser destruída para que se obtenha a madeira" (ARENDT, 2010, p. 173). Na visão da filósofa: "a característica da fabricação é ter um começo definido e um fim definido e previsível, e essa característica é bastante para distingui-la de todas as outras atividades humanas" (ARENDT, 2010, p. 179). Consiste na ideia de que o processo de fabricação é orientado sob um modelo, que pode ser tanto algo já visto "pelos olhos da mente" ou um esboço. Neste último, uma imagem que se reificou por meio da atividade do trabalho (ARENDT, 2010).

\footnotetext{
${ }^{8}$ Neste tópico, nos baseamos em uma seção da obra de Schio (2012) referente à ação humana, que tem como fundamento o livro "A condição humana" de Hannah Arendt. Primeiramente descreveremos brevemente o estudo desta filósofa para adentrarmos no estudo específico de Schio (2012) acerca da poíesis e práxis.
} 
Neste sentido, o homem exerce esta atividade para atingir um fim, isto é, um produto, que seja útil para os demais seres humanos. É também pelo processo de fabricação que são providas ao homem a experiência da instrumentalidade que determina todo trabalho (ARENDT, 2010). Em analogia à técnica, que diz respeito a capacidade do homem na aplicação do conhecimento em "como fazer" alguma coisa, conforme as situações que demandam esta capacidade, o homem terá habilidade e experiência em suas atividades. Sendo assim, no processo de fabricação, o homem transforma por meio da técnica a matéria-prima da natureza em objeto de uso.

Diferentemente do labor e do trabalho, a ação depende "[...] inteiramente da pluralidade humana, da presença constante de outros que possam ver e ouvir e, portanto, atestar sua existência" (ARENDT, 2010, p. 117). Ainda segundo a filósofa, é por meio de palavras e atos que cada um aparece (se revela) perante os outros, como também é um modo de se inserir no mundo, estimulado pelo desejo de nos juntarmos à presença dos outros. Ação e discurso mantêm a vida do homem, a pluralidade, e a convivência entre os homens, pois “[...] uma vida sem discurso e sem ação [...] deixa de ser uma vida humana, uma vez que já não é vivida entre os homens" (ARENDT, 2010, p. 221). Neste sentido, é característico do homem a ação e o discurso, tanto para a sua inserção como para a manutenção da sua vida em sociedade.

Ademais, uma ação sem discurso perde o seu caráter revelador, isto é, o que o agente está fazendo e sua identidade pessoal única (quem ele é) (ARENDT, 2010). Com base neste apontamento, a comunicação é fundamental para a ação humana, pois segundo Schio (2012, p. 174): "Os homens demonstram sua identidade ao expressar-se, no dizer, por isso o silêncio e a inação podem ocultá-lo. A revelação ocorre na convivência humana, na esfera pública". Deste modo, a ação torna-se a condição humana da pluralidade (ARENDT, 2010), isto é, na convivência entre os homens o ser humano busca praticar a liberdade, ouvir, discutir e deliberar, aspecto característico da política (SCHIO, 2012). Mediante tais apontamentos, a ação por si só é uma forma de política, pois demanda tanto "o agir" (tomar iniciativa) quanto o discurso para haver a pluralidade e assim a convivência harmoniosa na sociedade.

Na visão de Teles (2005, p. 133): "para a autora [Hannah Arendt], a política ocorre no diálogo do $e u$ com os outros, com o fito de se comunicarem e chegarem a um acordo". Neste sentido, a ação busca resolver questões e/ou atenuar conflitos, e isto acontece na política (SCHIO, 2012). Portanto, a ação e o discurso conferem um modo de revelar a identidade e singularidade do indivíduo, como também o seu caráter de cidadão. 
De acordo com Schio (2012) o pensamento de Hannah Arendt se aproxima do aristotélico quando a filósofa expõe a vida ativa e distingue as três atividades - o labor, o trabalho e a ação. Nas atividades da vida ativa há aspectos característicos tanto da poíesis, como por exemplo, a atividade do trabalho, que extrai a matéria-prima da natureza e reifica um objeto com o uso da técnica, quanto da práxis, relacionada à ação política que visa um fim em si mesma.

Sendo assim, adentramos no estudo dos aspectos da dimensão prática do ser humano, o fazer e o agir (NEDEL, 2007; WOLF, 2010) com base em Schio (2012). Esta autora retoma alguns dos conceitos aristotélicos para mostrar e desenvolver a tese de que ambas, poíesis e práxis possuem características comuns, apesar de serem distintas no campo da ação humana: "[...] ambas são contingentes, precisam da decisão (prohairesis) e ocorrem na atividade humana" (SCHIO, 2012, p. 155). Ademais, também visam algo, isto é, um fim, que transcende a própria ação, ocorrendo especificadamente na poíesis:

[...] o "produzir tem uma finalidade diferente de si mesmo", ou seja, o produto, momento que se distingue da práxis, pois "a boa ação é o seu próprio fim", isto é, a execução de algo visa a que este atingia esse algo, não um objeto acabado, como ocorre na poíesis (SCHIO, 2012, p. 155).

Ambas, poíesis e práxis, ocorrem no campo da atividade humana, apresentam um fim e durante o processo da ação há decisões. O que difere é: na poíesis, a ação finda em algo diferente dos atos de produzir, isto é, um produto. Já na práxis, a ação visa a própria ação, como por exemplo, ter atos justos termina numa ação justa. Para Schio (2012) a distinção entre ambas também está relacionada ao agente, com o que ele pretende ou objetiva. $\mathrm{Na}$ práxis, a intenção do agente pode ser percebida no valor da sua ação, como por exemplo, se a ação foi boa ou má. Isto se relaciona com a virtude do ser humano ao expor o seu caráter. Na poíesis está no fazer de qualidade (excelência) percebida no produto.

Para Arendt (2010, p. 191) durante o processo do trabalho "[...] tudo é julgado em termos de adequação e serventia [usefulness] em relação ao fim desejado". Esta filósofa nos mostra que no ato de fabricação o ser humano precisa de um modelo materializado (produto acabado) ou um esboço mental para orientar-se, e assim tornar a matéria-prima no objeto de uso. Neste processo, há a necessidade, em todo momento, em julgar e decidir para a escolha do material e técnica (método, regras) para a fabricação. Contudo, ambas, poíesis e práxis, perpassam por um processo de ponderação: 
No agir, o indivíduo pode elencar hipóteses (que pertencem à theoria) como na produção, desembocando em um processo deliberativo e findando em escolhas, o que não é contraditório, é possível de ocorrer tanto na práxis quanto na poíesis (SCHIO, 2012, p. 155-156).

Ainda segundo a autora, para atingir um fim, “[...] ambas geram um processo, estando por isso, relacionadas com pensamentos práticos que usam a prohairesis para determinar o desenvolvimento da atividade" (SCHIO, 2012, p. 156). A partir deste apontamento, poíesis e práxis admitem um processo que envolve decisões para definir o "rumo" da atividade, o que significa que há sempre um vínculo entre a práxis e a poíesis, indicando que ambas pertencem à ação humana, porém são diferentes uma em relação à outra.

Portanto, como a técnica possui vínculo com a poíesis, ou seja, a tékhne (habilidade para fabricar) se manifesta e torna-se perceptível por meio da ação da fabricação ou mediante o seu produto final (CHAUI, 2002), podemos afirmar que a poíesis é a ação que condiciona o indivíduo a passar por um processo (etapas) para se obter um fim por meio de julgamentos e decisões.

Em analogia à competência em informação e para resolver um problema ou questão informacional, o indivíduo perpassa por um processo, constituído por etapas, tais como a busca, a avaliação e o uso da informação. Isto demanda do indivíduo habilidades, julgamentos e consequentemente decisões. Para Brand-Gruwel, Wopereis e Vermetten (2005) o indivíduo competente em informação possui habilidades e sub-habilidades envolvidas para a resolução de um problema informacional, como por exemplo, a habilidade em "buscar a informação" e as sub-habilidades, "especificar termos de busca" e "julgar os resultados da busca".

Portanto, podemos afirmar que em Aristóteles (2003) e no âmbito da razão, especificamente na parte deliberativa, encontramos a distinção entre o "fazer/produzir" da técnica e "o agir" da práxis. Em Arendt (2010), e de acordo com Schio (2012) o pensamento de Hannah Arendt se aproxima do aristotélico quando expõe a vida ativa e a distingue das três atividades - o labor, o trabalho e a ação. Nas atividades da vida ativa há aspectos característicos tanto da poíesis, como por exemplo, a atividade do trabalho, que extrai a matéria-prima da natureza e reifica um objeto com o uso da técnica, quanto da práxis, relacionada à ação política que visa um fim em si mesma.

Nestas duas obras, emerge a caracterização da dimensão técnica da competência em informação: esta abarca tanto o "ser hábil" (o conhecimento para fazer) quanto os julgamentos e decisões para encontrar uma informação útil para resolver o problema informacional do 
indivíduo. O quadro 1 sintetiza o sentido da dimensão técnica da competência em informação sob este prisma:

Quadro 1: O sentido da dimensão técnica em Aristóteles e Hannah Arendt

\section{A TÉCNICA NA FILOSOFIA}

\section{Aristóteles}

Técnica como ação humana: toda ação visa a um fim ou a uma finalidade. $\mathrm{O}$ indivíduo pode agir do melhor modo possível em consonância com o equilíbrio das suas virtudes. Elementos racionais e irracionais da alma, são responsáveis pela formação das virtudes e que por sua vez, influenciam as nossas ações. A virtude ética se relaciona às "paixões e desejos", enquanto a virtude intelectual está relacionada às ações e à razão. A primeira se refere às boas ações e/ou atos virtuosos e ao "agir bem" (moralmente) e, a segunda orienta para a "medida certa" (nem excesso, nem carência) dos atos humanos - esta última surge do ensino e requer experiência e tempo.

\section{Hannah Arendt}

Dentre as atividades que condicionam a existência do homem há o labor, o trabalho e a ação. O labor diz respeito à atividade de subsistência, isto é, produzir para consumir, e assim assegurar o processo vital e a sobrevivência humana. Já o trabalho consiste na ideia de que o processo de fabricação é orientado sob um modelo e que

\section{O SENTIDO DA DIMENSÃO TÉCNICA} NA CIÊNCIA DA INFORMAÇÃO

A dimensão técnica da competência em informação é a ação que visa à resolução de um problema, necessidade ou oportunidade informacional.

A dimensão técnica da competência em informação ocorre por meio do equilíbrio das virtudes morais (éticas) e intelectuais (racionais), as quais se orientam por "boas ações" na medida certa à necessidade informacional.

A dimensão técnica da competência em informação requer o equilíbrio entre sentimentos, razão, e desejo, alinhados ao alcance de um fim: obter a informação para a necessidade pessoal. Demanda ensino, experiência, prática, tempo e reflexão.

Por meio do trabalho (conjunto de atividades que visam a produção de produtos e serviços informacionais) o processo informacional e a dimensão técnica da competência em informação se orientam sob um modelo e para um fim: o uso da informação

A dimensão técnica da competência em 
tem como fim a utilidade. Os resultados desta atividade são os objetos/produtos para uso do homem. A ação é revelada pela palavra e no anúncio do que se faz, do que se fez e do que se pretende fazer. O que permite diferenciar uns indivíduos em relação aos outros é a associação do discurso à ação. A presença do outro (alteridade) torna-se elemento essencial para a pluralidade. $\mathrm{Na}$ ação ocorrem decisões, as quais demandam julgamentos em termos de adequação ao fim desejado. $\mathrm{O}$ indivíduo perpassa por um processo, constituído por julgamentos e decisões. informação tem como fim a utilidade e se revela no discurso e na comunicação do resultado obtido no processo de busca informacional

A dimensão técnica da competência em informação ocorre por meio de um processo constituído por etapas (busca, avaliação e uso da informação) que demandam habilidades, julgamentos e decisões do indivíduo.

Fonte: elaborado a partir da literatura e da pesquisa realizada pelos autores (OLIVEIRA; VITORINO, 2014).

\section{A dimensão técnica da competência em informação}

La técnica es ambígua. Puede constituir una enorme ayuda para el hombre [...]. Pero se há convertido también, por otra parte en instrumento de disminución de las libertades (BERCIANO V.,

[1991], p. 61).

Até agora, caracterizamos a técnica sob o foco da Filosofia e a ela reservamos um lugar que talvez ainda não tenha sido explorado na literatura e que se refere aos julgamentos e decisões para resolver as necessidades e problemas informacionais.

Com base na literatura da Ciência da Informação e para demonstrar o vínculo entre estes aspectos da técnica e a competência em informação, alguns autores apresentam elementos que as constituem, colocando a técnica num lugar devido: como uma das dimensões desta "metacompetência".

Shapiro e Huges (1996), por exemplo, articulam a competência em informação e a Computer Literacy como habilidades técnicas essenciais. No entanto, a competência em informação se estende além da habilidade de utilizar os computadores e acessar a informação para "[...] uma reflexão crítica sobre a própria natureza da informação, sua infraestrutura técnica, e seu contexto social, cultural e até mesmo filosófico" (SHAPIRO; HUGES, 1996, 
tradução nossa). A competência em informação transcende determinadas habilidades, como por exemplo, o uso operacional do computador para acessar a informação (o domínio das tecnologias). Para estes autores a competência em informação se torna uma condição para a democracia (cidadãos conscientes para o uso/aplicação da informação). Ercegovac (1998) identifica cinco fases do "ciclo de vida da informação" (expressão correspondente às etapas que o indivíduo percorre para encontrar a informação). Segundo a autora, este ciclo demanda do indivíduo a competência em informação, isto é, um conjunto de habilidades para identificar a necessidade informacional (expressá-la sob forma de consulta no sistema de busca), acessar, buscar, e recuperar a informação (saber como as fontes informacionais estão organizadas e estruturadas; reconhecer os metadados que compõem um registro bibliográfico), e por fim a capacidade de avaliar e usar a informação.

Bruce (1999) caracteriza as "sete faces" da competência em informação. São concepções que emergiram do estudo acerca da experiência de um grupo de indivíduos (dentre estes, bibliotecários, analistas de sistemas e acadêmicos), em relação à competência em informação no ambiente de trabalho: primeira face: a competência em informação é vista como a experiência do indivíduo em usar as tecnologias; segunda face: a competência em informação é vista como a experiência do indivíduo em buscar a informação em fontes apropriadas; terceira face: a competência em informação é vista como a experiência do indivíduo na execução de um processo informacional a fim de resolver um problema; quarta face: a competência em informação é vista como a experiência do indivíduo em ter o controle/gerenciamento da informação para recuperá-la posteriormente; quinta face: a competência em informação é vista como a experiência do indivíduo em construir uma base de conhecimento pessoal em uma nova área de interesse; sexta face: a competência em informação é vista como a experiência do indivíduo em trabalhar com a perspectiva pessoal e conhecimento a fim de adquirir novos insights (ideias); sétima face: a competência em informação é vista como a experiência do indivíduo em usar a informação com sabedoria (baseada em valores pessoais e éticos), para benefício próprio como também para colegas e usuários (coletividade) (BRUCE, 1999).

Além de identificar essas faces e/ou concepções conforme experiência dos indivíduos, a autora conceitua a competência em informação como:

[...] a capacidade para as pessoas operarem eficazmente na Sociedade da Informação. Isto requer pensamento crítico, consciência ética pessoal e profissional, avaliar a informação, identificar necessidades de informação, organizar a informação, interagir com profissionais da informação e fazer 
uso eficaz da informação na resolução de problemas, tomada de decisão e pesquisa (BRUCE, 1999, p. 46, tradução nossa).

Os apontamentos da autora apresentam as dimensões da competência em informação: o uso das tecnologias para encontrar a informação (dimensão técnica), o feeling para compreender e relacionar novas informações a fim de obter ideias ou conhecimentos (dimensão estética) e o uso da informação acompanhado dos valores éticos do indivíduo para o bem comum da coletividade (dimensão ética e política).

Lloyd (2005) explora uma concepção autointitulada como "alternativa" para a competência em informação, que se refere à experiência de um grupo de bombeiros no uso da informação para o desenvolvimento da prática de trabalho.

De acordo com a autora, a competência em informação auxilia o indivíduo a compreender o ambiente de trabalho da instituição, construir a identidade enquanto trabalhador e aprender a trabalhar em equipe, por meio do acesso a diferentes fontes informacionais. Nomeadamente, as informações estão disponíveis nos documentos administrativos, políticas, manuais de procedimentos, textos produzidos e formalizados pela própria empresa/instituição (fonte institucional); na comunicação entre os profissionais (fonte social) e na demonstração física/prática das atividades de trabalho por um profissional $^{9}$ (fonte física) (LLOYD, 2005). Ser competente em informação requer do indivíduo habilidades para interagir com as diferentes tipologias de fontes informacionais a fim da inserção social e desenvolvimento da prática de trabalho.

Na visão de Eisenberg (2008, p. 40, tradução nossa) a competência em informação:

[...] é o conjunto de habilidades e conhecimentos que não só nos permite encontrar, avaliar e utilizar as informações que precisamos, mas talvez o mais importante, nos permite filtrar a informação que não precisamos. Habilidades da competência em informação são as ferramentas necessárias que nos ajudam a navegar com sucesso no presente e futuro do cenário informacional.

O autor ressalta as habilidades como "ferramentas", isto é, "uso" das habilidades associadas às tecnologias para facilitar a localização, avaliação e uso das informações. Contudo, também é fundamental o pensamento crítico para filtrar as informações.

Em uma das primeiras publicações no Brasil sobre a temática competência em informação, Dudziak (2003) conceitua o termo Information Literacy como o

\footnotetext{
${ }^{9} \mathrm{O}$ profissional adquire a informação de "como fazer" a atividade de trabalho visualizando a prática de outro profissional.
} 
[...] processo contínuo de internalização de fundamentos conceituais, atitudinais e de habilidades necessário à compreensão e interação permanente com o universo informacional e sua dinâmica, de modo a proporcionar um aprendizado ao longo da vida (DUDZIAK, 2003, p. 28).

Ainda conforme esta autora, existem diferentes níveis de complexidade do conceito de competência em informação. No nível básico, a competência em informação é concebida como habilidade para o uso das ferramentas informacionais e da tecnologia, a chamada Alfabetização Digital ou Computer Literacy. No nível secundário, a competência em informação é caracterizada como a internalização de habilidades e conhecimentos construídos pela reflexão. Por último, no nível mais complexo, a competência em informação é considerada como um constante processo de aprendizado, englobando habilidades, conhecimentos, valores e atitudes voltadas ao aprender a aprender e à responsabilidade social (DUDZIAK, 2007).

No contexto do trabalho, Miranda (2006) aborda a competência em informação sob o enfoque de três dimensões: o saber (conhecimentos), saber-fazer (habilidades) e o saberser/agir (atitudes). Competência em informação é o conjunto destes recursos colocados em ação nas situações práticas que envolvem o trabalho com a informação (MIRANDA, 2006).

Já Gasque (2010, p. 86) utiliza o termo Letramento Informacional (correspondente à competência em informação) que consiste: "[...] no engajamento do sujeito nesse processo de aprendizagem a fim de desenvolver competências e habilidades necessárias à busca e ao uso da informação de modo eficiente e eficaz". O Letramento Informacional promove o aprendizado e geração de conhecimento, resultado da interação com as informações, reflexão, experiência prévia, bem como as relações do indivíduo com o contexto social (GASQUE, 2010).

Como podemos notar, nos conceitos sobre competência em informação, tanto em nível nacional como internacional, para ser competente em informação é preciso ser hábil, isto é, saber-fazer (conhecimento aplicado na prática da atividade) para encontrar, avaliar e usar a informação. Há também que considerar que a "reflexão" é um componente mencionado repetidas vezes pelos autores, o que reforça ainda mais o sentido da dimensão técnica quando articulado a Filosofia e a Ciência da Informação. Diante disso, a dimensão técnica se configura como a base/sustentação para o desenvolvimento da competência em informação para que o indivíduo posteriormente tenha também a habilidade para usar a informação com ética e sabedoria em diferentes situações e contextos da vida. 
Para demonstrar que além da habilidade para atingir um fim de uma ação, o indivíduo também passa por um processo que admite julgamentos e consequentemente decisões durante uma atividade informacional, explicitamos um dos diversos $\operatorname{modelos}^{10}$ para o desenvolvimento da competência em informação existentes na literatura em Ciência da Informação: Model for Information Problem Solving.

Com base no The Big6, Brand-Gruwel, Wopereis e Vermetten (2005) estruturaram um novo modelo para a resolução de problemas informacionais. Após aplicarem uma tarefa (problema informacional) a doutores (pesquisadores experientes) e calouros de graduação (pesquisadores iniciantes) de universidades holandesas, os autores identificaram e descreveram hierarquicamente as habilidades e sub-habilidades envolvidas no processo de resolução do problema informacional conforme figura 2.

Figura 2 - Habilidades para a resolução do problema informacional

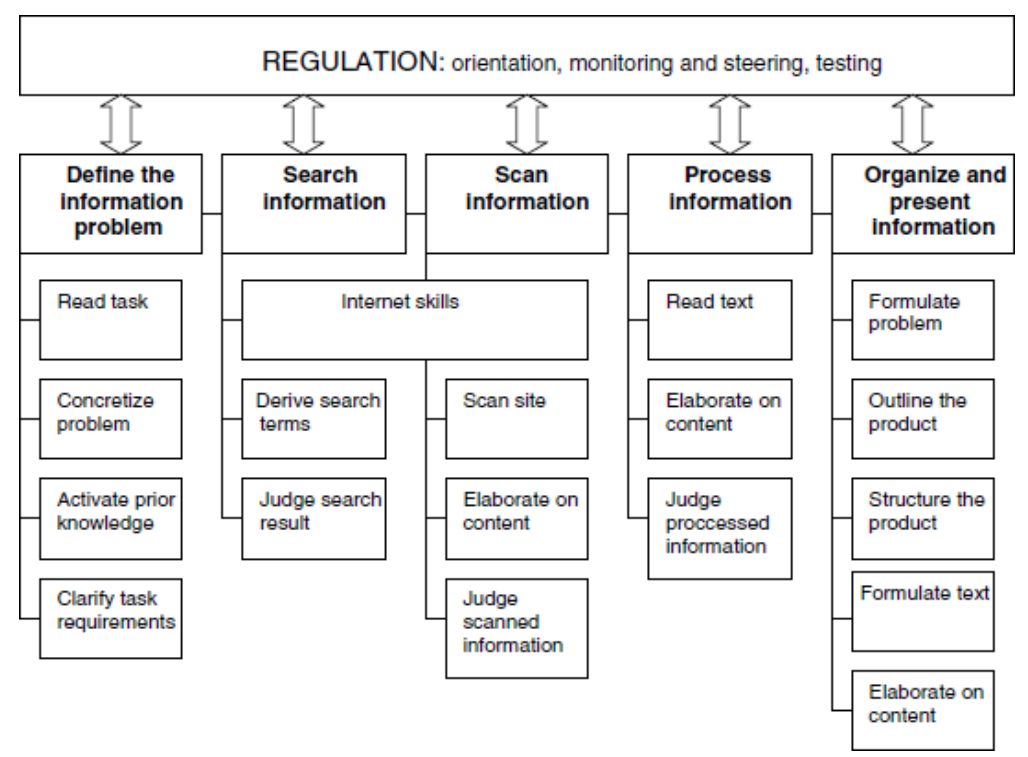

Fonte: Brand-Gruwel, Wopereis e Vermetten (2005).

O processo de resolução do problema informacional consiste em cinco habilidades principais, dezoito sub-habilidades e uma habilidade de regulamentação (regulation skill) (BRAND-GRUWEL; WOPEREIS; VERMETTEN, 2005).

10 Os modelos indicam um processo, procedimento ou sistema representado graficamente. Permitem a compreensão, análise e potenciais melhorias das ações dos indivíduos no processo da busca da informação. São utilizados por bibliotecários e educadores em diferentes áreas, como por exemplo, Engenharia, Educação, Administração e Ciência da Informação, no desenvolvimento da competência em informação (GROSS; ARMSTRONG; LATHAM, 2012). Segundo este autores, há uma variedade de modelos na literatura em Ciência da Informação, porém dois dos modelos mais adotados para o ensino são The Information Search Process (ISP) Model e The Big6 (GROSS; ARMSTRONG; LATHAM, 2012). 
Como nos modelos anteriores, o processo se inicia com a atribuição de uma tarefa (problema). A habilidade em "definir o problema informacional" (define the information problem skill) é mobilizada para se obter uma visão da tarefa. É fundamental ler com atenção os requisitos da tarefa. Formular perguntas ajuda a entender o que é preciso fazer (concretizar o problema). O conhecimento prévio é acionado para definir a informação a ser buscada. No fim desta etapa, os requisitos da tarefa já estão esclarecidos para o indivíduo (BRANDGRUWEL; WOPEREIS; VERMETTEN, 2005).

A próxima etapa demanda a habilidade em "buscar a informação" (search information skill). Momento que o indivíduo formula os termos/palavras-chave para iniciar a busca na fonte de informação ${ }^{11}$, obtém e julga os resultados conforme qualidade, relevância e confiabilidade (BRAND-GRUWEL; WOPEREIS; VERMETTEN, 2005). O conjunto de habilidades empregado nesta etapa é importante para verificar a pertinência do resultado da busca. Constatada a sua relevância prossegue-se para a próxima etapa. Do contrário, uma nova estratégia de busca deverá ser formulada.

Após obter os resultados pertinentes, o indivíduo realiza uma leitura rápida da informação (scan information skill) e faz o julgamento para decidir sobre a seleção dos resultados (quais informações serão previamente utilizadas). Os critérios de julgamento dependerão do problema e do tipo de informação necessária, bem como da qualidade, confiabilidade e relevância. No decorrer da leitura, ocorrerá o aprofundamento sobre o conteúdo (elaboration on the content), ou seja, novas informações serão combinadas com o conhecimento prévio do indivíduo (BRAND-GRUWEL; WOPEREIS; VERMETTEN, 2005). Consequentemente, promoverá a aprendizagem e a "especialização" do indivíduo em torno do tema.

Da seleção dos resultados, na próxima etapa, o indivíduo reúne e processa em profundidade as informações (process information skill), ou seja, lê, analisa, seleciona e estrutura a informação (aprofundamento sobre o conteúdo). Mais uma vez é importante julgar as informações conforme a qualidade e utilidade. O objetivo final desta etapa é reunir a informação e compreendê-la a fim de utilizá-la na resolução do problema (BRANDGRUWEL; WOPEREIS; VERMETTEN, 2005).

A habilidade em "organizar e apresentar a informação" (organize and present information skill) refere-se à última etapa, momento do indivíduo criar o produto conforme os

${ }^{11} \mathrm{O}$ estudo utilizou como fonte informacional a Internet. Dentre as habilidades necessárias para o processo de resolução informacional estão as "habilidades em internet" (internet skills), isto é, um conjunto de habilidades para o uso/navegação da internet. 
requisitos da tarefa. Escrever um ensaio é um tipo de produto, porém existem outros, como por exemplo, um cartaz ou uma apresentação. Nesta etapa, o indivíduo formula o problema (indagação que o conduz à criação do produto), delineia e estrutura o formato, como por exemplo, um sumário prévio contendo as seções a serem trabalhadas para a formulação do texto (BRAND-GRUWEL; WOPEREIS; VERMETTEN, 2005).

$\mathrm{Na}$ execução do processo, a habilidade em "regulamentação" (regulation skill) é mobilizada para o indivíduo acompanhar e orientar a própria tarefa, gerenciar o tempo, desenvolver o conteúdo e avaliar o produto e processo. Perguntas podem e devem ser realizadas para orientar e monitorar as atividades, como por exemplo: é esta a informação que eu preciso? Quais são os requisitos/exigências da tarefa? São necessários outros termos/palavras-chave para pesquisar? Tenho informação suficiente para trabalhar? (BRANDGRUWEL; WOPEREIS; VERMETTEN, 2005).

O processo é movido por julgamentos e decisões com a finalidade de solucionar o problema informacional. As indagações auxiliam o indivíduo a refletir sobre o processo e quanto ao produto final, e na auto-orientação para a execução das atividades, ou seja, decidir o que fazer após o término de cada etapa. Por exemplo, se no fim do processo o indivíduo comparar as informações com o problema (requisitos da tarefa) e constatar que não há informações suficientes, decidirá pela busca de novas informações.

Deste modo, habilidades sustentadas por julgamentos e decisões são mobilizadas na resolução de problemas informacionais, o que denota que a teorização inicialmente apresentada e extraída de Aristóteles e de Arendt são úteis à compreensão e explicação da dimensão técnica da competência em informação: esta abarca tanto o "ser hábil" (o conhecimento para fazer) quanto o "ser reflexivo", que se utiliza de julgamentos e decisões para encontrar uma informação útil e resolver o problema informacional.

\section{Considerações Finais}

Se por um lado, o vocábulo "técnica", revela a nós pesquisadores a sua complexidade, por outro, esclarece outras características conceituais à dimensão técnica da competência em informação.

Diferentes conceitos na literatura em Ciência da Informação foram analisados e demonstraram que os indivíduos durante o processo de busca mobilizam habilidades para localizar, avaliar e usar a informação. Por sua vez, as decisões findam na escolha do tema da 
pesquisa, nos termos e nas fontes de informação para a elaboração da estratégia de busca, mas também na avaliação e na seleção dos resultados da busca (BRAND-GRUWEL; WOPEREIS; VERMETTEN, 2005; EISENBERG, 2008; KUHLTHAU, 1999). Neste sentido, "nasceu” o aperfeiçoamento conceitual: a dimensão técnica da competência em informação é a ação que visa à resolução de um problema, necessidade ou oportunidade informacional, ocorre por meio do equilíbrio das virtudes morais (éticas) e intelectuais (racionais), as quais se orientam por "boas ações" na medida certa à necessidade informacional. Requer paixão e razão, nem desejo somente, nem intelecto somente: a medida certa (a justa medida) e a prudência, alcançadas por meio do ensino, da experiência, da prática, do tempo e da reflexão. Por meio do trabalho (conjunto de atividades que visam a produção de produtos e serviços informacionais), é que o processo informacional e a dimensão técnica da competência em informação se orientam para um fim. A dimensão técnica da competência em informação ocorre, de fato, por meio de um processo constituído por etapas que demandam habilidades, julgamentos e decisões do indivíduo - o "ser reflexivo".

Em cada ação/atividade durante a busca informacional, o indivíduo se depara com escolhas em seu "fazer": "qual a melhor fonte de informação?”, "quais estratégias de buscas utilizar?", "quais informações dos resultados de busca da pesquisa posso selecionar?”, "quais informações utilizar?". A fim de escolher entre os diferentes caminhos e recursos informacionais o indivíduo faz julgamentos que resultam em decisões e que apontam para a localização da informação, e, assim, para a solução do seu problema informacional.

Deste modo, o indivíduo diante de situações informacionais mobiliza a dimensão técnica, isto é, põe em prática o seu conhecimento para "o fazer informacional", sustentado por julgamentos e decisões. O sentido da técnica, como uma das dimensões da competência em informação, se materializa na "justa medida” entre educação, experiência, prática, tempo e reflexão.

\section{REFERÊNCIAS}

ABBAGNANO, Nicola. Dicionário de filosofia. 5. ed. rev. e ampl. São Paulo: Martins Fontes, 2007. 1210 p.

AMERICAN LIBRAY ASSOCIATION (ALA). Center for the Future of Libraries. Libray of the future: trends. 2015. Disponível em: <http://www.ala.org/transforminglibraries /future/trends>. Acesso em: 11 maio 2015. 
ARENDT, Hannah. A condição humana. Tradução Roberto Raposo. Revisão Técnica Adriano Correia. 11. ed. Rio de Janeiro: Forense Universitária, 2010. 407 p.

ARISTÓTELES. Ética a Nicômaco: Aristóteles : texto integral. Tradução Pietro Nassetti. São Paulo: Martin Claret, 2003. 240 p.

BERCIANO V., Modesto. La técnica moderna. Refleciones ontológicas. Universidad de Oviedo. Servicio de Publicaciones, Espanha, [1991]. 133 p.

BRAND-GRUWEL, Saskia; WOPEREIS, Iwan; VERMETTEN, Yvonne. Information problem solving by experts and novices: analysis of a complex cognitive skill. Computers in Human Behavior, v. 21, n. 3, p. 487-508, May 2005. Disponível em: <http://www.sciencedirect.com/science/article/pii/S0747563204001591>. Acesso em: 07 ago. 2013.

BRUCE, Christine. Workplace experiences of information literacy. International Journal of Information Management, v. 19, n. 1, p. 33-47, Feb. 1999. Disponível em: <http://www.sciencedirect.com/science/article/pii/S0268401298000450>. Acesso em: 18 set. 2013.

CHAUI, Marilena de Souza. Introdução à história da filosofia: dos pré-socráticos a Aristóteles. 2. ed. rev. e aum. São Paulo: Companhia das Letras, 2002.539 p.

DUDZIAK, Elisabeth Adriana. Information Literacy: princípios, filosofia e prática. Ciência da Informação, Brasília, v.32, n.1, p. 23-35, jan./abr. 2003. Disponível em: <http://www.scielo.br/scielo.php?script=sci_arttext\&pid=S0100-196520030001 00003\&lang=pt>. Acesso em: 29 out. 2013.

DUDZIAK, Elisabeth Adriana. O bibliotecário como agente de transformação em uma sociedade complexa: integração entre ciência, tecnologia, desenvolvimento e inclusão social. PontodeAcesso, Salvador, v.1, n.1, p. 88-98, jun. 2007. Disponível em: <http://www. portalseer.ufba.br/index.php/revistaici/article/view/1396/878>. Acesso em: 29 out. 2013.

EISENBERG, Michael B. Information Literacy: essential skills for the Information Age. DESIDOC Journal of Library \& Information Technology, v. 28, n.2, p. 39-47, Mar. 2008. Disponível em: <http://search.ebscohost.com/login.aspx?direct=true\&dB=lih\&AN= 51198131\&lang=pt-br\&site=ehost-live >. Acesso em: 22 out. 2013.

GARCÍA BACCA, Juan David. Elogio de la técnica. Barcelona: Anthropos, 1987. 152 p.

GASQUE, Kelley Cristine Gonçalves Dias. Arcabouço conceitual do letramento informacional. Ciência da Informação, Brasília, v. 39, n. 3, p. 83-92, set./dez. 2010. Disponível em: <http://www.scielo.br/pdf/ci/v39n3/v39n3a07.pdf〉. Acesso em: 31 out. 2013.

GIACOIA JUNIOR, Oswaldo. Pequeno dicionário de filosofia contemporâneo. São Paulo: Publifolha, 2006. 183 p.

GIL, Antonio Carlos. Métodos e técnicas de pesquisa social. 6. ed. São Paulo: Atlas, 2008. $200 \mathrm{p}$. 
GROSS, Melissa; ARMSTRONG, Bonnie; LATHAM, Don. The Analyze, Search, Evaluate (ASE) Process Model: three steps toward information literacy. Community \& Junior College Libraries, v.18, p.103-118, 2012. Disponível em: <http://dx.doi.org/10.1080/ 02763915.2012.780488>. Acesso em: 07 nov. 2013.

KUHLTHAU, Carol Collier. O papel da biblioteca escolar no processo de aprendizagem. In: VIANNA, Márcia Milton; CAMPELLO, Bernadete; MOURA, Victor Hugo Vieira. Biblioteca escolar: espaço de ação pedagógica. Belo Horizonte: EB/UFMG, 1999. p. 9-14. Disponível em: <http://gebe.eci.ufmg.br/downloads/103.pdf>. Acesso em: 05 nov. 2013.

LIZ, Manuel. Conocer y actuar a través de la tecnologia. In: BRONCANO, Fernando (ed.). Nuevas meditaciones sobre la técnica. Madrid: Editorial Trotta, 1995. p. 23-51.

LLOYD, Annemaree. Information literacy: different contexts, different concepts, different truths? Journal of Librarianship and Information Science, v. 37, n.2, p. 82-88, June 2005. Disponível em: <http://lis.sagepub.com/content/37/2/82.full.pdf+html>. Acesso em: 15 out. 2013.

MARCONI, Marina de Andrade; LAKATOS, Eva Maria. Técnicas de pesquisa: planejamento e execução de pesquisas, amostragens e técnicas de pesquisa, elaboração, análise e interpretação de dados. 7. ed. São Paulo: Atlas, 2012. 277 p.

MIRANDA, Silvânia. Como as necessidades de informação podem se relacionar com as competências informacionais. Ciência da Informação, Brasília, v. 35, n. 3, p. 99-114, set./dez. 2006. Disponível em: 〈http://www.scielo.br/pdf/ci/v35n3/v35n3a10.pdf>. Acesso em: 27 ago. 2013.

MORAES, Eduardo Jardim de Moraes. Hannah Arendt: filosofia e política. In: BIGNOTTO, Newton (Org.). Hannah Arendt: diálogos, reflexões, memórias. Belo Horizonte: UFMG, 2001. p. 35-47.

NEDEL, José. Reflexões sobre arte e técnica. Cultura e fé, v. 30, n.117, p. 60-96, 2007.

NODARI, Paulo César. A ética aristotélica: felicidade como o bem supremo em Aristóteles. In: Sobre ética: Aristóteles, Kant e Levinas. Caxias do Sul: Educs, 2010. p. 13-47.

OLIVEIRA, Alexandre Pedro de; VITORINO, Elizete Vieira. A dimensão técnica da Competência Informacional: visão dos bibliotecários de referência das bibliotecas universitárias da Grande Florianópolis, SC. In: ENCONTRO NACIONAL DE PESQUISA EM CIÊNCIA DA INFORMAÇÃO (ENANCIB), 15., 2014, Belo Horizonte. Anais... Belo Horizonte: ECI/UFMG, 2014. p. 2703-2722. Disponível em: < http://enancib2014.eci. ufmg.br/documentos/anais/anais-gt6>. Acesso em: 22 fev. 2016.

PERRIN, Jacques. Por uma cultura técnica. In: SCHEPS, Ruth (Org.). O império das técnicas. Campinas: Papirus, 1996. p. 103-110.

RIOS, Terezinha Azerêdo. Compreender e ensinar: por uma docência de melhor qualidade. 6 ed. São Paulo: Cortez, 2006. 
SCHIO, Sônia Maria. Hannah Arendt: história e liberdade: da ação à reflexão. 2. ed. Porto Alegre: Clarinete, 2012. 263 p.

SHAPIRO, Jeremy J.; HUGHES, Shelley K. Information Literacy as a liberal art: enlightenment proposals for a new curriculum. Educom Review, v. 31, n. 2, mar./abr. 1996. Sem paginação. Disponível em: <http://net.educause.edu/apps/er/review/reviewArticles/ 31231.html>. Acesso em: 14 set. 2013.

TELES, Edson Luis de Almeida. Práxis e poiesis: uma leitura arendtiana do agir político. Cadernos de Ética e Filosofia Política, n. 6, p. 123-140, 2005. Disponível em: <http://www.fflch.usp.br/df/cefp/Cefp6/teles.pdf>. Acesso em: jul. 2013.

VITORINO, Elizete Vieira; PIANTOLA, Daniela. Dimensões da competência informacional. Ciência da Informação, Brasília, v.40, n.1, p.99-110, jan./abr. 2011. Disponível em: <http://revista.ibict.br/ciinf/index.php/ciinf/article/view/1918/1397>. Acesso em: 14 maio 2012.

WOLF, Ursula. A Ética a Nicômaco de Aristóteles. Tradução Enio Paulo Giachini. São Paulo: Edições Loyola, 2010. 286 p.

ZINGANO, Marco. Aristóteles: tratado da virtude moral : Ethica Nicomachea I 13 - III 8. São Paulo: Odysseus Editora, 2008. 223 p. 